\title{
EXPERIMENTAL INVESTIGATION AND NUMERICAL SIMULATION OF THE CORRELATION OF RECOVERY AND TEXTURE IN BCC METALS AND ALLOYS
}

\author{
D. RAABE, F. ROTERS and V. MARX \\ Collaborative Research Center for Materials Modelling, Institut für \\ Metallkunde und Metallphysik, Rheinisch-Westfälische Technische \\ Hochschule Aachen, Kopernikusstr. 14, 52056 Aachen, Germany
}

(Received 20 July 1995)

\begin{abstract}
Depending on the strain and temperature regime examined recovery of bcc metals during hot rolling or annealing subsequent to cold deformation often leads to the preservation of certain deformation texture components. A broad variety of mesoscopic and macroscopic texture data from both hot rolled and cold rolled and annealed bcc metals $(\mathrm{Fe}, \mathrm{Ta}, \mathrm{Mo}, \mathrm{Nb}$ ) and alloys (low-carbon steels, ferritic stainless steels, transformer steels) is re-examined with respect to such phenomena. The data suggest that two conditions promote strong recovery of certain bcc deformation texture components (e.g. $\{001\}$ $<110>$ ), namely, the absence of kinetic instabilities, and the absence of thermodynamic and mechanic instabilities. The first case applies if the grains do not tend to generate large local misorientations in their interiors during plastic deformation. The second case applies if the stored dislocation density is low. Both features depend on the grain orientation. The experimental observations are complemented by three types of numerical simulations. The influence of the number of Burgers vectors equally involved during preceding deformation on the kinetics of static recovery is numerically studied using 2 dimensional dislocation dynamics. The orientation dependent inclination to generate local misorientations in the grain interiors is simulated using a Taylor type approach with different constraints on either side of the grain. The influence of the orientation dependence of recovery on the final annealing texture is simulated using a 3 dimensional cellular automation. Experiment and simulation show that both the recovery kinetics and the tendency to form kinetic instabilities considerably depend on the orientation. The latter effect seems to be essential for the prevalence of either RX or RC.
\end{abstract}

KEY WORDS: Texture, recovery, body centered cubic, EBSD, simulation, 2D dislocation dynamics, Taylor model, cellular automaton.

\section{INTRODUCTION}

For the onset of primary recrystallization (RX) a thermodynamic, mechanic and kinetic instability is required (e.g. Cahn 1966, Gottstein 1984, Haessner 1984). The first type of instability is referred to as nucleation, the second one as net driving force and the

Correspondence to: Dr.-Ing. Dierk Raabe, Institut für Metallkunde und Metallphysik, Kopernikusstr. 14, Rheinisch-Westfälische Technische Hochschule Aachen, 52056 Aachen. Tel: +49-241-806866/ 806855 Fax: +49-241-8888-301 E-mail: raabe@hp1.imm.rwth-aachen.de. 
third one as motion of high-angle grain boundaries. If one of these instability conditions is not fulfilled recovery (RC) instead of RX may prevail. Such behavior is often observed during annealing of weakly deformed samples. However, it is less well established that even in case of strong cold reduction prior to annealing RX of certain texture components can be considerably delayed or even suppressed due to the crystallographic texture (Hu 1962, 1963, Raabe 1992, Raabe 1995).

The textures of bcc alloys arising from $\mathrm{RX}$ were the subject of numerous studies (Wassermann and Grewen 1962, Walter and Koch 1963, Hu 1962, 1963, Dillamore 1984, Hutchinson 1984, 1989, Raabe and Lücke 1992, 1993, Raabe et al. 1994, Lindh et al. 1994). In some investigations it was suggested that the RX tendency of $\{111\}$ $<$ uvw > crystals is due to their relatively large dislocation content (Lebrun et al. 1978, Smith and Dillamore 1974), their small dislocation cell size, and sufficiently large misorientations in the grain interiors which provide adequate nucleation sites (Inokuti and Doherty 1977, 1978, Doherty 1984, Dillamore et al. 1967, 1972). Such approaches were experimentally confirmed by use of transmission electron microscopy (Takechi et al. 1968, Dillamore et al. 1967, 1972), EBSD (Raabe and Lücke 1992, 1994, Raabe 1995) and internal stress measurements (Lebrun et al. 1978, Smith and Dillamore 1974, Klimanek 1995). High nucleation rates within $\{111\}<$ uvw $>$ oriented grains were especially found in the vicinity of grain boundaries (Hutchinson 1989), deformation bands (Inokuti and Doherty 1977, 1978), and close to shear bands (Raabe 1995). The Taylor factor which is referred to as approximate measure for the slip activity indeed reveals a minimum value for $\{001\}<110>$ and maximum values for $\{111\}$ $<u v w>$ and $\{110\}<u v w>$ oriented grains. This corresponds to the frequently made observation that $\{001\}<110>$ is very sluggish to recrystallize whereas the latter texture components show a strong tendency to recrystallize.

Whilst the orientation dependence of RX has been thoroughly addressed for both single- and polycrystals, only few studies have focused on the orientation dependence of recovery of bcc metals and alloys. Hu $(1962,1963)$ was the first to thoroughly investigate the recovery behavior of cold rolled silicon-iron single crystals. In these studies Hu observed that especially $\{001\}<110>$ and $\{001\}<100>$ oriented crystals were reluctant to recrystallize. Recently various authors addressed the strong orientation dependence of RC in polycrystalline low carbon steels (Raabe 1993, 1995), polycrystalline Ta (Raabe et al. 1993, 1994) Mo and Nb (Raabe and Lücke 1994) and ferritic stainless steels (Raabe and Luicke 1992). Although other authors concentrated on the occurrence of $\{111\}<\mathrm{uvw}>$ oriented grains at the early stages of RX they also observed the sluggish RX behavior of the $\{001\}<110>$ component (Kern and Bunge 1984, Plutka and Hougardy 1991).

During RX newly formed large angle grain boundaries which have the kinematic freedom to sweep as incoherent interfaces through the deformed matrix, discontinuously change the texture and the strength of the metal. The generation of thermodynamic instabilities requires an incubation period. The process naturally comes to an end when the new grains impinge. In contrast, during RC a continuous softening but no reorientation of the affected grains takes place. Static $\mathrm{RC}$ does not require an incubation period. Following current dislocation based models (Nabarro 1989, Nes 1995) we assume that RC is essentially controlled by cross slip, thermally activated glide, and climb.

Owing to the mechanisms involved at first sight it appears obvious that texture investigation is an appropriate diagnostic means of distinguishing between RX and RC. However, one must emphasize that the preservation of certain texture components during annealing of deformed bcc metals is not necessarily due to RC. It is conceivable that 
a texture component which is stable during deformation, is discontinuously removed by growing RX nuclei and at the same time in a different region of the same sample newly generated by oriented nucleation or growth selection. In bcc metals the $\{111\}$ $<110>$ texture component represents such a component which is among the main orientations in both cold rolled (plain strain) and recrystallized samples. It follows that an analysis of statistical RC textures (X-ray diffraction experiments) should be accompanied by texture investigations in the micro- or mesoscopic regime and by microstructural studies.

Besides fundamental aspects their are also engineering reasons to investigate $\mathrm{RC}$ of bcc metals. Strong RC of grains with a low Taylor factor (e.g. $\{001\}<110>$ and related components on the $\alpha$-fiber) during hot rolling of low carbon steels is beneficial for the subsequent cold rolling process. It leads to texture softening and thus decreases the required rolling forces. In contrast, during annealing of cold rolled low-carbon steels, ferritic stainless steels and bcc refractory metals RC must be avoided because the so preserved texture components considerably deteriorate the deep drawing properties.

The current investigation is concerned with the re-examination of crystallographic textures stemming from a broad variety of bcc transition metals and related alloys with special regard to RC. For this purpose we first review the textures observed after hot rolling and second the textures arising from cold rolling annealing. The experimental data were determined by employing texture measurements in the macroscopic and mesoscopic regime together with microstructure investigations. For complementing the experimental work three types of simulations are included for interpreting the orientation dependence of RC. First, for assessing the RC kinetics of different texture components the influence of the number of involved Burgers vectors is numerically studied using space discretized 2 dimensional (2D) dislocation dynamics. Second, the orientation dependent tendency for the generation of local misorientations in the grain interiors is simulated using a Taylor type approach. In this model the formation of local misorientations is attributed to the influence of the neighbouring crystals. Third, the influence of orientation dependent RC on the final annealing texture is simulated using a 3 dimensional (3D) cellular automaton.

Based on the experimentally achieved and simulated data it is aimed to clarify whether the absence of thermodynamic, mechanic or kinetic instabilities represents the crucial condition for the prevalence of RC during annealing of heavily deformed bcc metals.

\section{EXPERIMENTAL RESULTS}

\subsection{Materials and Experimental Techniques}

In this study, we review experimental data obtained from polycrystalline $\mathrm{Fe}, \mathrm{Ta}, \mathrm{Mo}$, $\mathrm{Nb}$, low carbon steels, ferritic stainless steels and Fe-Si transformer steels. The chemical composition of some alloys which are discussed in greater detail are given in Table 1. The low carbon steels had a grain size within the range $20-40 \mu \mathrm{m}$ after hot rolling and the pure refractory metals within the range 70-80 $\mu \mathrm{m}$. The ferritic stainless steels (Table 1) had a bimodal grain size distribution with small equiaxed recrystallized grains $(10-20 \mu \mathrm{m})$ and flat elongated ones (100-200 $\mu \mathrm{m}$ in rolling direction). In addition to such conventional samples polycrystalline aggregates consisting of only a few large grains with a longitudinal extension of $10-20 \mathrm{~mm}$ and a transverse extension of 2-6 mm were re-examined. These specimens are convenient for studying RC in grain 
Table 1 Chemical composition of some alloys which are discussed in greater detail (alloy content is given in mass\%).

\begin{tabular}{|c|c|c|c|c|c|c|c|c|c|c|c|}
\hline & $\mathrm{Cr}$ & $C$ & $N$ & $N b$ & $T i$ & $A l$ & $M n$ & $P$ & $S$ & $F e$ & $T a$ \\
\hline $\begin{array}{l}\text { Low carbon } \\
\text { steel }\end{array}$ & - & 0.019 & 0.003 & - & - & 0.04 & 0.2 & 0.008 & 0.012 & balan. & - \\
\hline $\begin{array}{l}\text { Bcc stainless } \\
\text { steel }(\sim 11 \% \mathrm{Cr})\end{array}$ & 10.5 & 0.01 & 0.02 & 0.32 & 0.11 & - & - & - & - & balan. & - \\
\hline $\begin{array}{l}\text { Bcc stainless } \\
\text { steel }(\sim 17 \% \mathrm{Cr})\end{array}$ & 16.6 & 0.02 & 0.02 & 0.64 & 0.01 & - & - & - & - & balan. & - \\
\hline $\mathrm{Ta}$ & - & 0.02 & 0.02 & 0.01 & 0.01 & - & - & - & - & - & balan. \\
\hline
\end{tabular}

scale, since the large grain size allows one to track the texture evolution of an individual grain during rolling and annealing. However, it must be considered that the deformation texture and microstructure, especially the degree of fragmentation and the resulting local texture gradients, depend on the grain size.

The microstructure was investigated using optical and scanning electron microscopy. The crystallographic texture was measure using both $\mathrm{X}$-ray and electron diffraction. In the first case the four incomplete pole figures $\{110\},\{200\},\{112\}$ and $\{103\}$ were determined in the back reflection mode using $\mathrm{Mo}_{\mathrm{K} \alpha}$ radiation. From the centrosymmetric pole figures the orientation distribution function (ODF) was calculated using the harmonic method of Bunge (1982). In the second case the texture was investigated in grain scale exploiting the orientation dependence of electron back scattering diffraction (EBSD) (Venables and Harland 1973). This technique represents a useful means of providing both, microstructure and texture data with a high spatial resolution. Details of the experimental technique employed are explained elsewhere (Engler and Gottstein 1992).

\subsection{Influence of Recovery on the Hot Rolling Textures of Steels}

Figure 1 shows the through-thickness texture profile of a hot rolled ferritic stainless steel with 16.6 mass $\% \mathrm{Cr}$ content (Table 1). Close to the sheet center a strong incomplete $\alpha$-fiber, $\{$ hkl $\}<110>$, ranging from $\{001\}<110>$ to $\{111\}<110>$, Figure 1a, and a pronounced $\gamma$-fiber, $\{111\}<\mathrm{uvw}>$, with a maximum at $\{111\}<110>$ are generated. Figures 1a,b. Close to the sheet surface a dominant Goss component, $\{110\}$ $<001>$, and a minor component close to $\{112\}<111>$ appears, Figure 1c (Raabe and Lücke 1993). The microstructure in the center layer consists of elongated flat grains. Recrystallized grains are rarely observed, Figure $2 \mathrm{a}$. In the sub-surface layers both finely recrystallized (arrow $A$ in Figure $2 b$ ) and elongated recovered grains appear. In the longitudinal sections it becomes apparent that some elongated grains reveal a heavily sheared shape (arrow $B$ in Figure $2 b$ ).

Following experimental results obtained from texture measurements of heavily sheared samples (Österle and Wever 1981) and simulations of the profile of equivalent shear through the sheet thickness of hot rolled steel sheets, Figure 3, (Beynon et al. 1987, McLaren and Sellars 1992, Fedosseev et al. 1994) we may interpret the hot band textures close to the surface in terms of heavy shear and the textures in the center layer in terms of plain strain deformation. Additionally, McLaren and Sellars (1993) showed on the basis of simulated and experimentally achieved data that the profile of equivalent shear promotes RC in the center layer and RX close to the sheet surface. This observation 


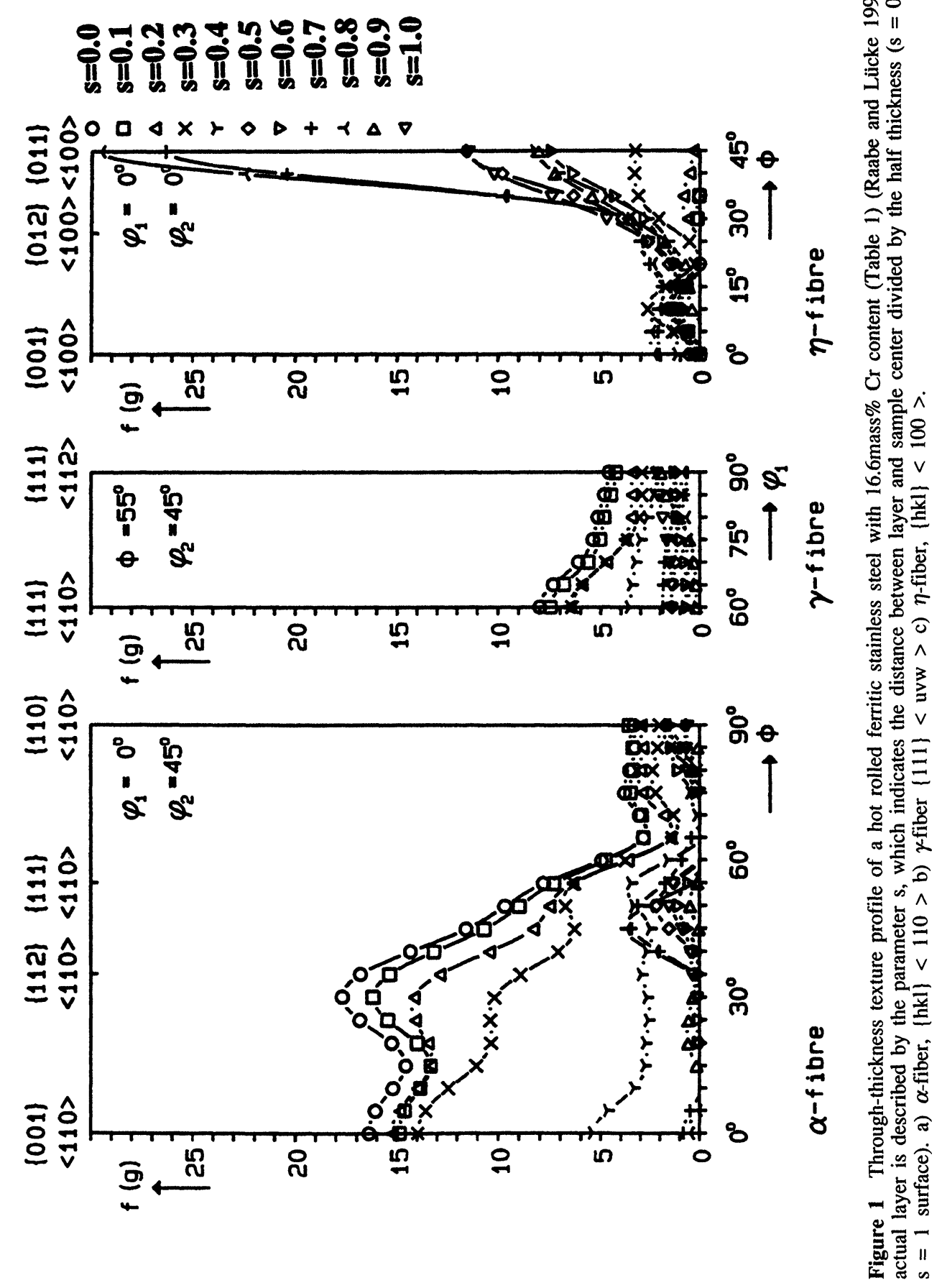



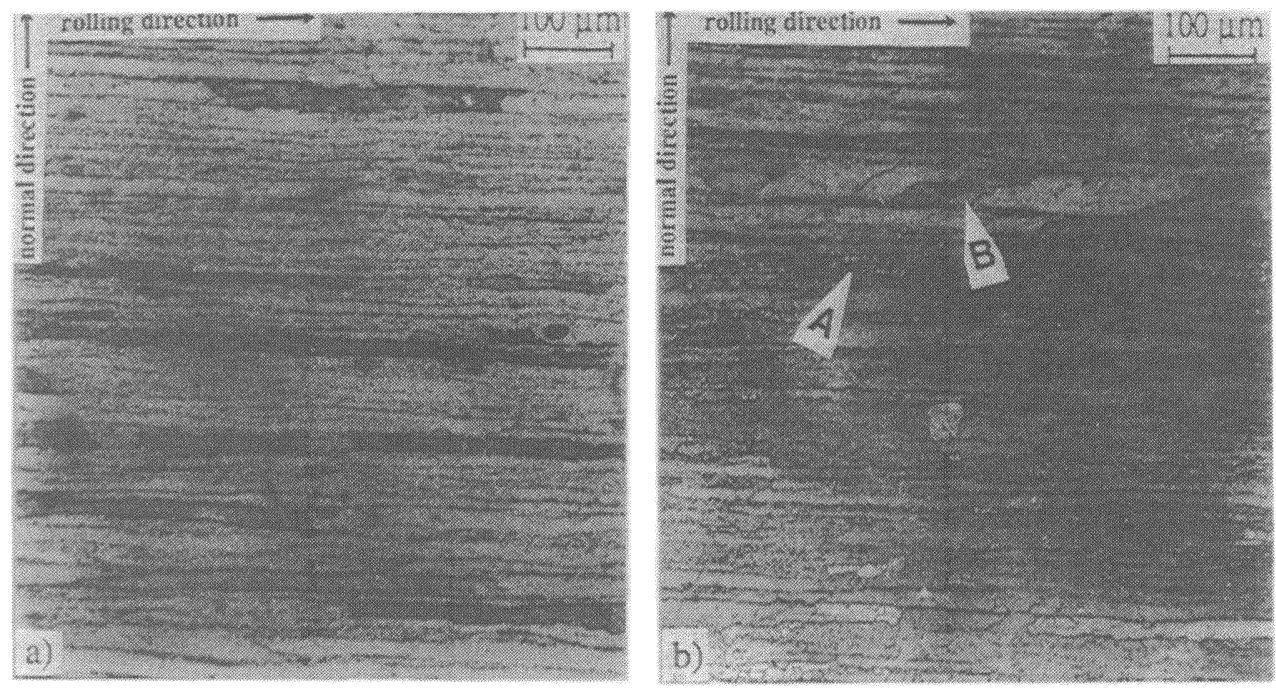

Figure 2 Microstructure of a hot rolled ferritic stainless steel with $16.6 \mathrm{mass} \% \mathrm{Cr}$ (Figure 1, Table 1). a) Center layer $(s=0)$ containing elongated flat grains. b) Sub-surface layer $(s=0.8)$ containing both finely recrystallized (arrow A) and elongated recovered grains. Some elongated grains reveal a heavily sheared shape (arrow B).

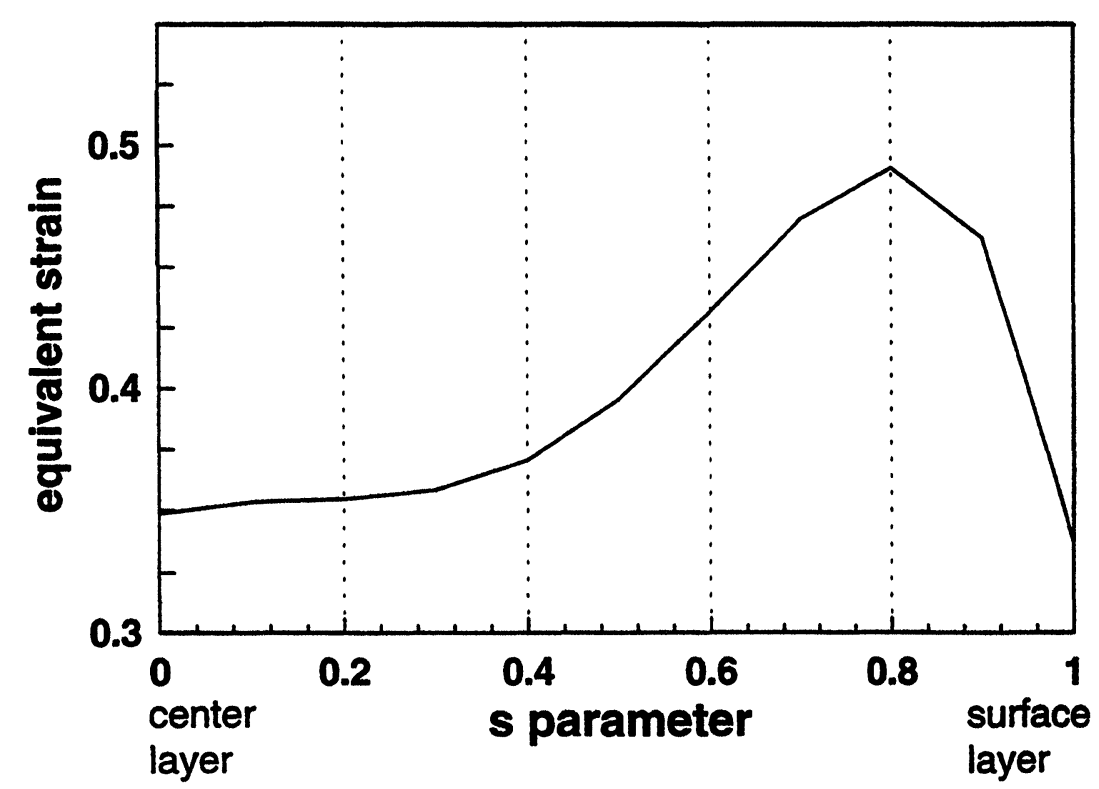

Figure 3 Simulation of the profile of equivalent shear through the sheet thickness of a hot rolled steel sheet (Beynon et al. 1987). 


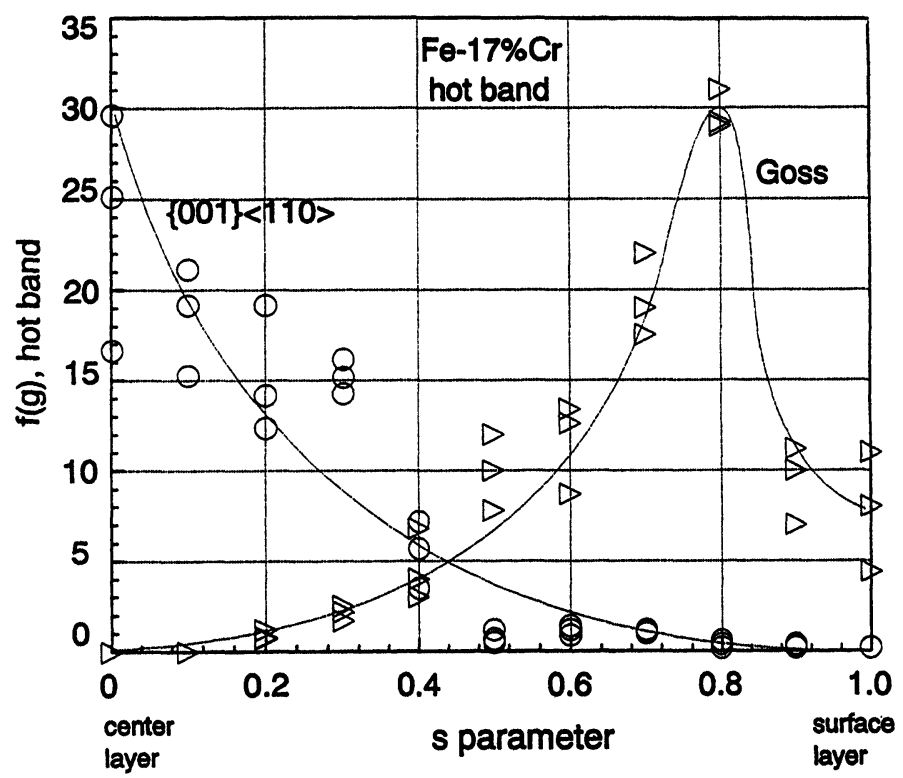

Figure 4 Profile of the orientation density of the $\{001\}<110>$ and of the Goss component through the hot band thickness of various ferritic stainless steels with $=17 \mathrm{mass} \% \mathrm{Cr}$ content.

corresponds to our results obtained from ferritic stainless steel hot bands. Figure 4 shows the profile of the orientation density of the $\{001\}<110>$ and of the Goss component through the hot band thickness. Raabe and Ylitalo (1995) recently showed that both texture components correspond to deformed rather than recrystallized grains. In accord with Figure 3 the distribution of both texture components suggests that the $\{001\}$ $<110>$ component arises from plain strain and the Goss component from shear deformation.

During hot rolling of steels two mechanisms can contribute to avoid strong texture components arising from plain strain or shear deformation, namely, phase transformation and RX. The volume fraction of material which is affected by phase transformation during hot rolling, especially during the last hot rolling passes, depends on the amount of foreign atoms stabilizing either the ferritic or the austenitic phase. Figure 5 shows the influence of $\mathrm{C}, \mathrm{Si}$ and $\mathrm{Cr}$ on the orientation density of the $\{001\}<110>$ texture component in the center layer of hot rolled and $90 \%$ cold rolled samples. From this diagram four main observations can be extracted. First, the orientation density of $\{001\}$ $<110>$ considerably increases with the $\mathrm{Si}$ and $\mathrm{Cr}$ content. Second, the influence of $\mathrm{Si}$ exceeds that of $\mathrm{Cr}$. Third, the $\{001\}<110>$ texture component is inherited from the hot rolling texture to the cold rolling texture. It is generated during hot rolling (center layer) and stabilized during cold rolling. Forth, neither the amount of plastic deformation nor the temperatures during hot rolling suffice to remove the $\{001\}$ $<110>$ texture component by RX. The last statement is underlined by a recent study on hot rolled ferritic stainless steel sheets (Raabe and Ylitalo 1995). In this study it was shown by use of EBSD measurements that the $\{001\}<110>$ component coincides neither with recrystallized or transformed, but exclusively with flat elongated recovered grains, Figure 6. 


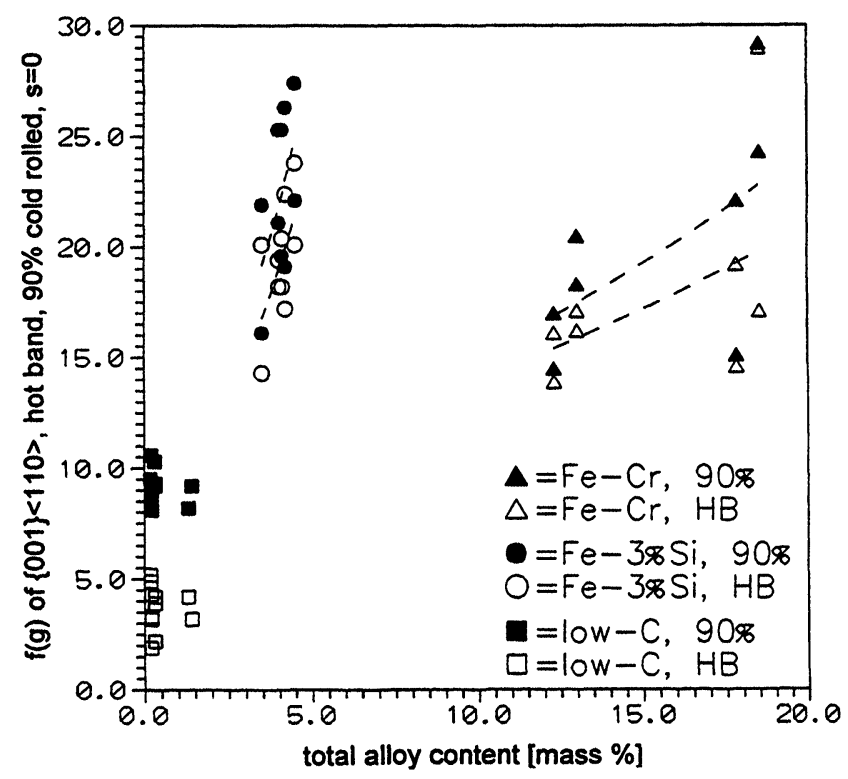

Figure 5 Influence of $\mathrm{C}, \mathrm{Si}$ and $\mathrm{Cr}$ on the orientation density of $\{001\}<110>$ in the center layer of hot rolled and $90 \%$ cold rolled samples. The open symbols indicate hot rolled band (HB) and the filled ones cold rolled band (90\%).

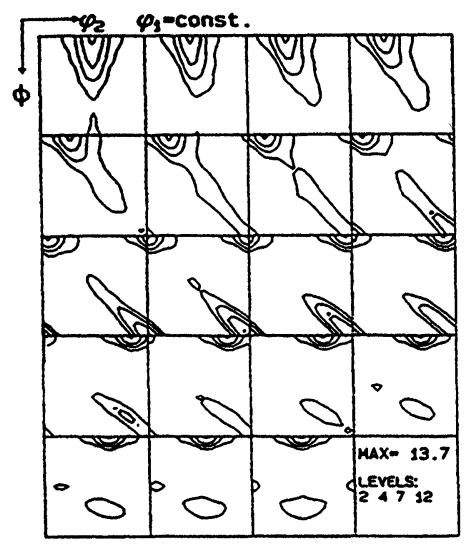

a)

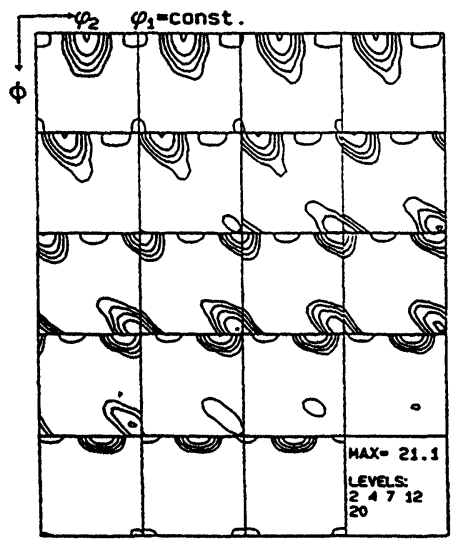

b)

Figure 6 Texture in the center layer of a hot rolled ferritic stainless steel with $=17 \mathrm{mass} \% \mathrm{Cr}$ content (Raabe and Ylitalo 1995) a) Texture as determined by use of X-ray diffraction (four incomplete pole figures). b) Texture of the flat elongated recovered grains as selectively determined by use of EBSD. 
The first two observations are readily explained in terms of the stabilizing influence of both $\mathrm{Cr}$ and $\mathrm{Si}$ on the ferritic phase (Houdremont 1956). This means the randomizing effect of phase transformation during hot rolling is suppressed with increasing $\mathrm{Cr}$ and $\mathrm{Si}$ content. The third result shows that the strain state during hot rolling (center layer) and cold rolling must be similar. The forth observation clearly shows that the $\{001\}$ $<110>$ component arises from strong RC and not from phase transformation or RX. However, for the moment it remains an open question why this texture component is not removed by $\mathrm{RX}$ but preserved by $\mathrm{RC}$.

\subsection{Influence of Recovery on the Annealing Textures of Cold Rolled Samples}

In the following three examples are reviewed where RC contributes to the texture formation during annealing after cold rolling, namely, low-carbon steel, ferritic stainless steel, and pure $\mathrm{Ta}$ as an example of high melting bcc transition metals.

The influence of $\mathrm{RC}$ on the texture formation in low- carbon steels was investigated using texture measurements both in the mesoscopic and macroscopic regime (Raabe 1995). An industrially hot rolled low carbon steel (Table 1) was cold rolled to a reduction of $\varepsilon=90 \%$. After cold rolling the specimens were heat treated at $1000 \mathrm{~K}$ in a salt bath for 1 to 300 s. The hardness and the orientation distribution of the non recrystallized grains were determined as a function of the annealing time. The texture of the rolled sample revealed an incomplete $\alpha$-fiber and a weak $\gamma$-fiber. According to the hardness curve RX started after $4 \mathrm{~s}$ and was completed after $10 \mathrm{~s}$. The texture determined via $\mathrm{X}$-ray diffraction shows that after $7 \mathrm{~s}$ the $\alpha$-fiber is considerably weakened, Figure $7 \mathrm{a}$. With further heat treatment the $\alpha$-fiber is decreased and the $[111\}<112>$ orientation becomes the strongest component of the texture. However, from these quantitative data no unequivocal statement can be made about the assignment of certain grains to certain texture components. For investigating whether recovered grains reveal a preferred orientation EBSD measurements were carried out, Figure $7 \mathrm{~b}$. Due to their flat elongated

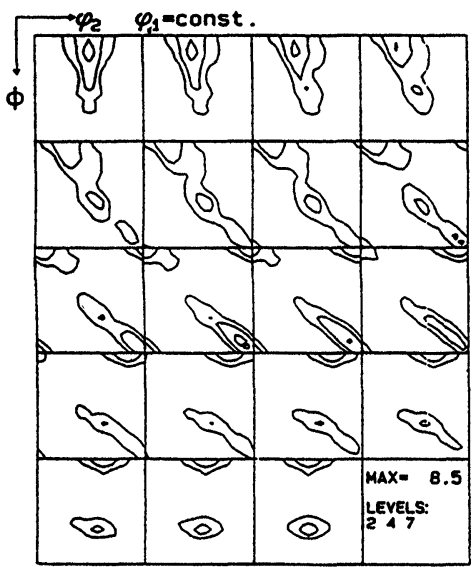

a)

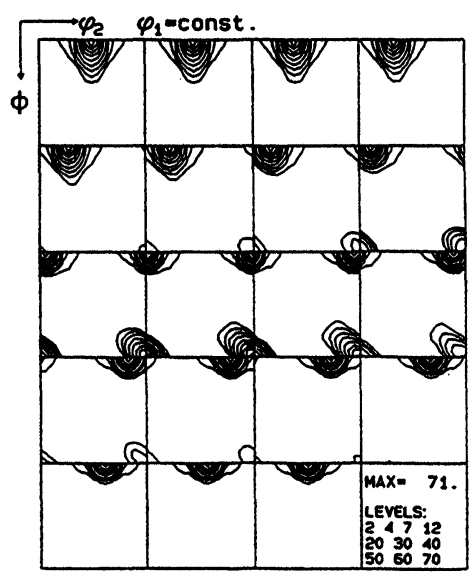

b)

Figure 7 Texture in the center layer of a $90 \%$ cold rolled and annealed low carbon steel (7 s, $1000 \mathrm{~K}$, salt bath), (Raabe 1995) a) Texture as determined by use of X-ray diffraction (four incomplete pole figures). b) Texture of the unrecrystallized grains as selectively determined by use of EBSD (arrow in Figure 8). 


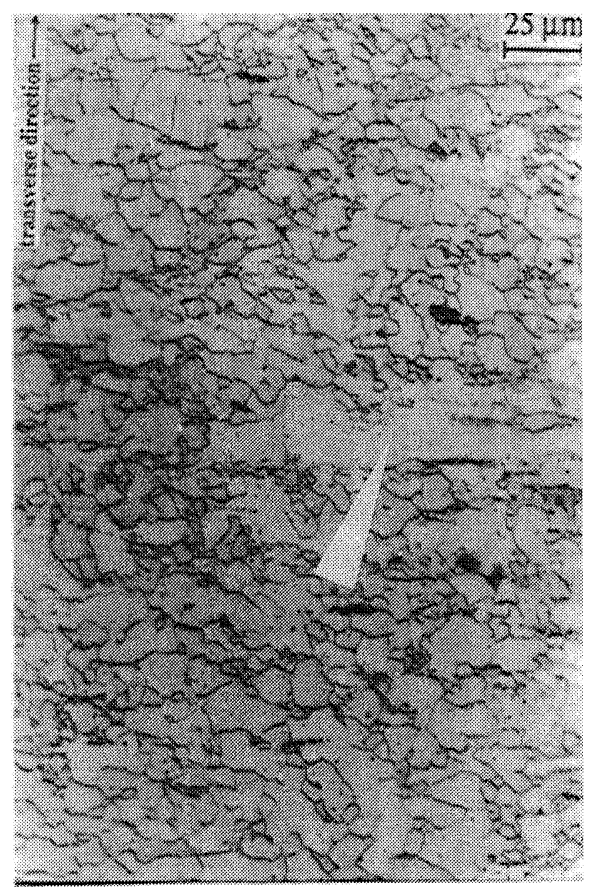

Figure 8 Flat sections of the $90 \%$ cold rolled and annealed $(7 \mathrm{~s}, 1000 \mathrm{~K}$, salt bath) low carbon steel sheet the texture of which was shown in Figure 7. Figure $7 \mathrm{~b}$ shows the texture of the recovered grains (arrow).

shape recovered crystals can easily be identified microscopically, Figure 8 . The texture which was calculated from 261 different non recrystallized grains after $7 \mathrm{~s}$ at $1000 \mathrm{~K}$, Figure $7 \mathrm{~b}$, reveals a very strong $\{001\}<110>$ component which is spread out about the rolling direction. That means nearly all grains which were not recrystallized after $7 \mathrm{~s}$ are characterized by a $\{001\}<110>$ orientation. In contrast, the texture of all grains which was obtained by $X$-ray diffraction. Figure $7 \mathrm{a}$, shows a weak $\{001\}$ $<110>,\{113\}<110>,\{111\}<110>$ and $\{111\}<112>$ orientation. This observation strongly suggests that in $\{001\}<110>$ oriented grains $\mathrm{RX}$ is considerably delayed as compared to $\{111\}<\mathrm{uvw}>$ oriented crystals. Such orientation dependent sluggishness to recrystallize leaves room for strong $\mathrm{RC}$.

For investigating the orientation dependence of static RC in more detail Raabe (1995) recently studied a low carbon steel with a large grain size. The samples were $90 \%$ cold rolled and annealed in a salt bath furnace $(1000 \mathrm{~K}, 120 \mathrm{~s})$, Figures 9, 10. Longer annealing times did not lead to further texture changes. The measurements substantiated that grains with a Taylor factor $M>3$ were less sluggish to recrystallize, Figure 9, as compared to grains with $M<3$, Figure 10 . From a very strong $\{111\}<112>$ rolling texture, Figure 9, a pronounced Goss accompanied by a weak $\{111\}$ $<110>$ component was generated. In contrast, the heat treatment of a specimen with a strong initial $\{001\}<110>$ component, Figure 10 , leads to a reduction of this orientation but not to its elimination. However, it must be emphasized that not only the Taylor factor but also the occurrence of sufficiently large misorientations in the grain interiors is a necessary precondition for the onset of RX. 

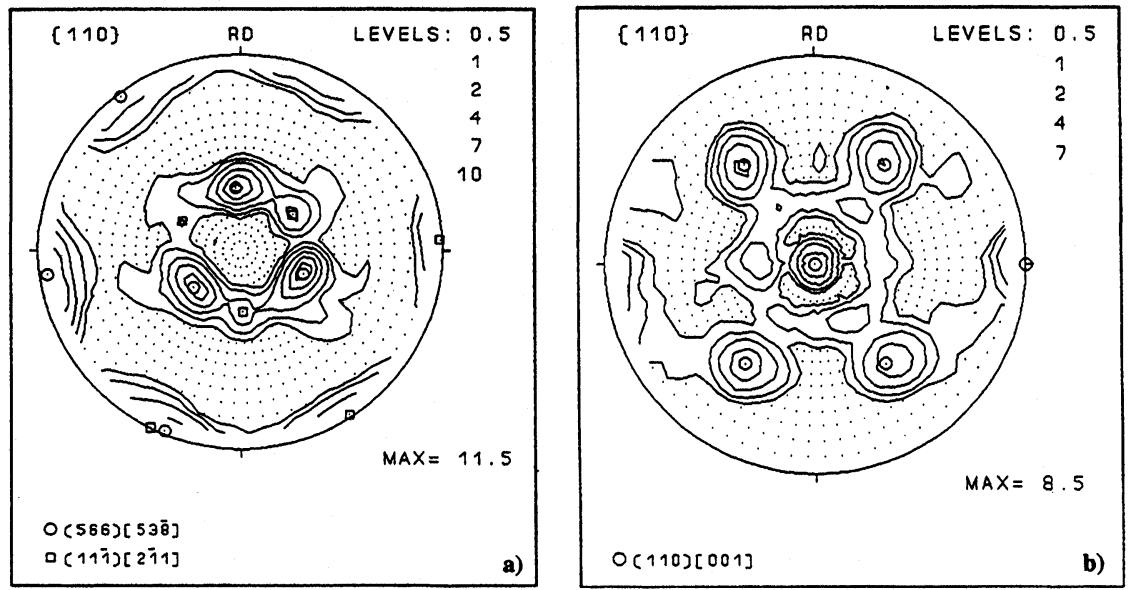

Figure $9\{110\}$ pole figures of a low carbon steel with a large grain size $\left(\mathrm{d}_{\text {grain }}=\mathrm{mm}\right)$ with a strong $\{111\}<112>$ component after cold rolling. a) $90 \%$ cold rolled. b) $90 \%$ cold rolled and 120 s annealed at $1000 \mathrm{~K}$ in a salt bath furnace.
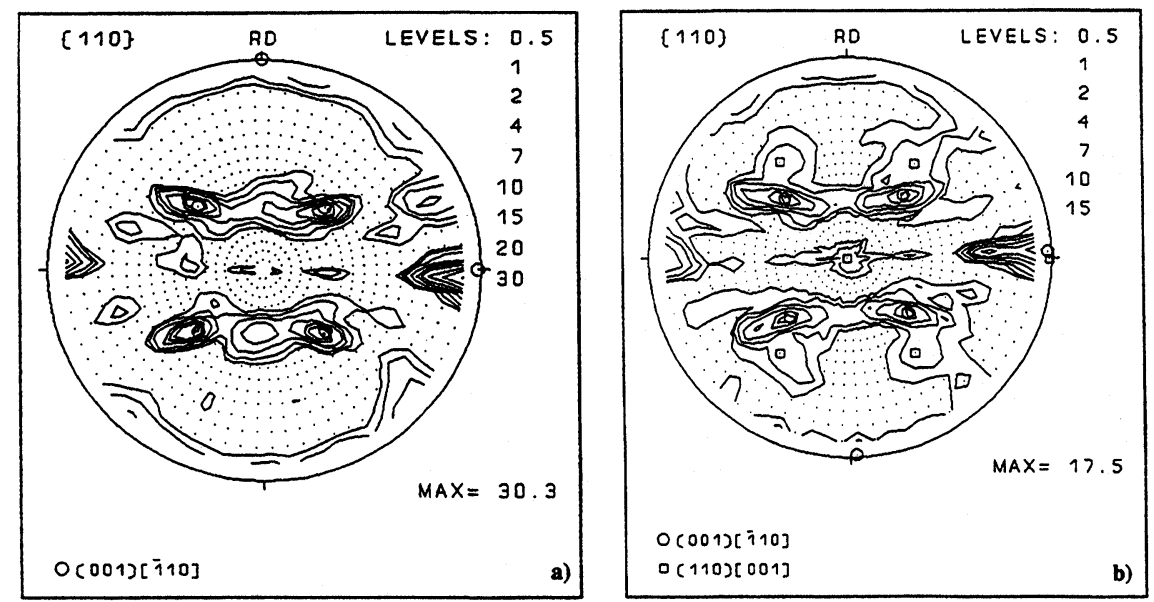

Figure $10\{110\}$ pole figures of a low carbon steel with a large grain size $\left(d_{\text {grain }}=m m\right)$ with a strong $\{001\}<110>$ component after cold rolling. a) $90 \%$ cold rolled. b) $90 \%$ cold rolled and $120 \mathrm{~s}$ annealed at $1000 \mathrm{~K}$ in a salt bath furnace.

The dependence of $\mathrm{RC}$ and $\mathrm{RX}$ in a low carbon steel was studied on local misorientations and strain constraints imposed by neighboring grains using EBSD texture measurements. For a large number of grains $\left(d_{\text {grain }} \approx \mathrm{mm}\right)$ both the microtexture and its dependence on the orientation of the neighboring grains was inspected, Figure 11. It was observed that soft crystals with a Taylor factor $\mathrm{M}<3$ which were surrounded by hard grains with $M>3$ (filled circles) did not reveal a large tendency to generate large misorientations in their interior. Correspondingly, hard grains with $M>3$ which were surrounded by soft ones with $\mathrm{M}<3$ (filled triangles) did also not tend to form 


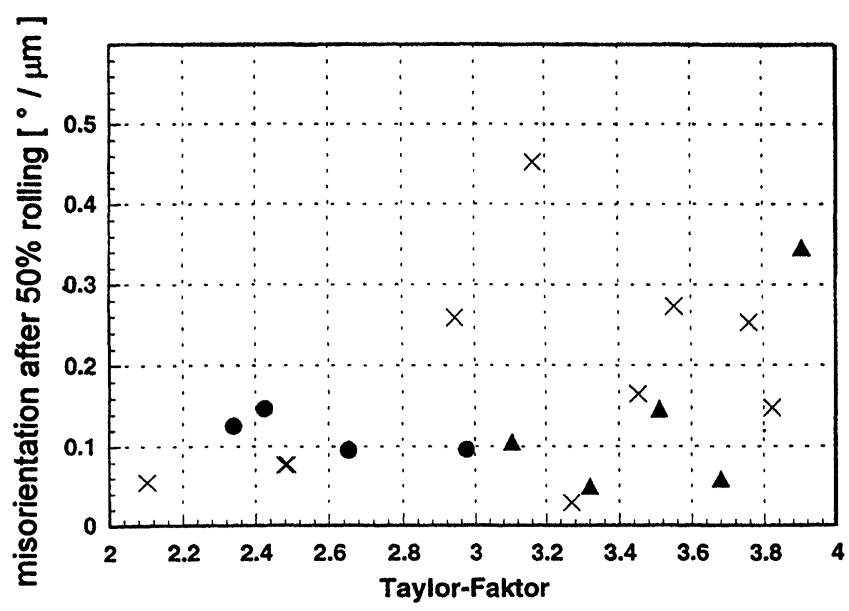

Figure 11 Misorientation in grain interiors after 50\% cold reduction, low carbon steel. Texture measurements by use EBSD. Filled circles: soft crystals with a Taylor factor $M<3$ which were surrounded by hard grains with $M>3$. Filled triangles: hard grains with $M>3$ which were surrounded by soft ones with $M<3$. Crosses: grains which were surrounded by both hard and soft crystals.

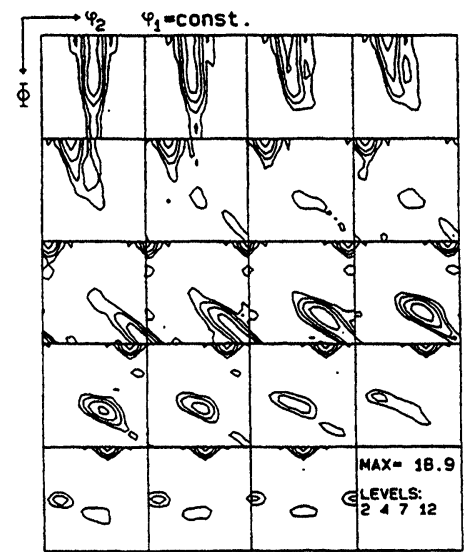

a)

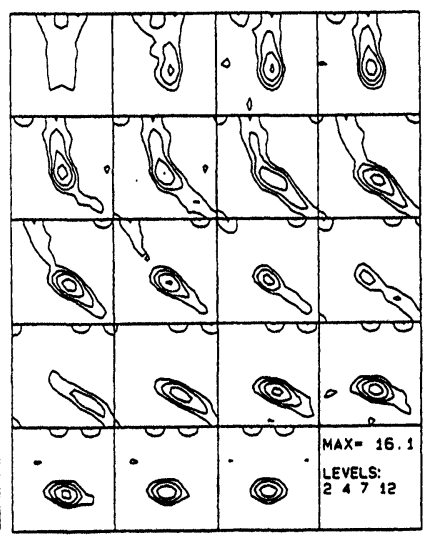

b)

Figure 12 Texture of a ferritic stainless steel with $10.5 \mathrm{mass} \% \mathrm{Cr}$ content measured in the center layer (Table 1). a) $90 \%$ cold rolled. b) $90 \%$ cold rolled and annealed at $1120 \mathrm{~K}$ in a salt bath furnace.

large local orientation gradients. However, grains which were surrounded by both hard and soft crystals (crosses) typically revealed large misorientations in their interior.

Similar observations as obtained in considerable detail from low carbon steels were made for cold rolled and annealed ferritic stainless steel with 10.5 mass $\% \mathrm{Cr}$ content (Table 1), Figure 12, and refractory metals, Figure 13. It is shown that the $\alpha$-fiber components within the range $\{001\}<110>$ to $\{112\}<110>$ are in both cases very sluggish to recrystallize. In pure $\mathrm{Ta}$ the orientation density of the $\{001\}$ 


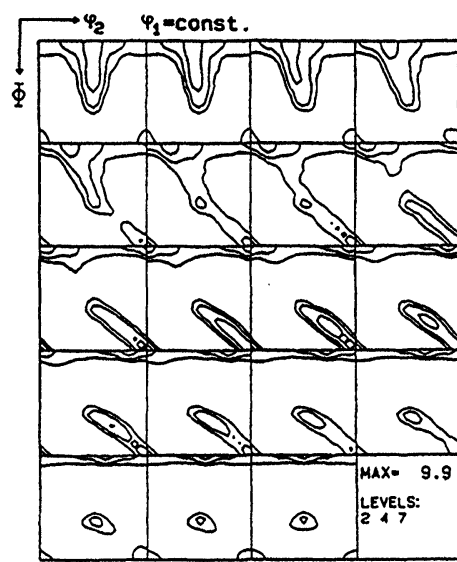

a)

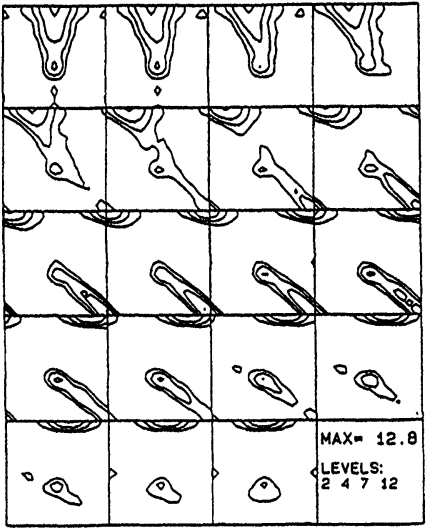

b)

Figure 13 Texture of pure polycrystalline Ta (Table 1) in the center layer. a) $70 \%$ cold rolled. b) $70 \%$ cold rolled and annealed at $1270 \mathrm{~K}$ in a vacuum furnace.

$<110>$ component even increases. Similar observations were made for pure and alloyed $\mathrm{Nb}$ and Mo polycrystals (Raabe and Lücke 1994).

\section{SIMULATION}

\subsection{Numerical Simulation of the Kinetics of Static Recovery}

Various analytical models are available for the description of RC (Nabarro 1989, Nes 1995). However, as far as the orientation dependence of RC is addressed these approaches reveal various shortcomings. First, the orientation dependence of the dislocation microstructure prior to the anneal is neglected. Whilst the orientation dependence of the cell size could be artificially introduced the types and numbers of involved Burgers vectors are generally neglected in these models. However, it is clearly shown by the above results that the influence of orientation seems to be crucial to the entire process. Second, no spatial arrangements of dislocations but only dislocation densities in the cell interior and in the cell walls are considered. Third, Nes (1995) stated that the analytical models presently in use are not able to explain the RC data observed for pure iron (Michalak and Paxton 1961). Since even in simple cases the presented analytical approaches are obviously not detailed enough to explain the present observations we simulate the orientation dependence of RC in bcc metals numerically.

In our approach we concentrate on the influence of the number of Burgers vectors involved during preceding large strain deformation on the kinetics of static RC. For this purpose we conduct a numerical study using space discretized $2 \mathrm{D}$ dislocation dynamics. In this approach we investigate how the kinetics of static RC are affected when a given initial dislocation density is either distributed on two or on four different slip systems prior to the anneal. The first case is regarded as an example of a grain with a little number of active slip systems (e.g. $\{001\}<110>$ ) and the second one as an example of a grain with a large number of active slip systems (e.g. $\{111\}$ $<110>$ ). 
A quadratic grain with a size of $5 \mu \mathrm{m} \cdot 5 \mu \mathrm{m}$ and geometrical boundary conditions is chosen as basic configuration. Screw dislocations are not considered since they reveal a much larger annihilation distance, a mutual centralforce type interaction and a high mobility perpendicular to their glide plane which altogether makes it easy for them to depart from their actual slip planes already during deformation. Consequently, we exclusively simulate the sluggish RC kinetics of the structurally relevant edge dislocations, which constitute the dislocation structure after heavy plastic deformation. At the beginning of the simulation the dislocations are inserted in a random manner, either distributed on two or on four different slip systems. In order to address only one parameter, viz. the number of involved slip systems, both grains have an identical initial dislocation density, $\rho_{\text {start }}=10^{14} \mathrm{~m}^{-2}$, prior to the anneal. The number of positive and negative dislocations is balanced. The portion of the total stress field contributed by each single $2 \mathrm{D}$ dislocation, $\sigma_{i}(r)$, is calculated according to the framework given for straight dislocations of infinite length (Hirth and Lothe, 1968). The total stress, $\sigma_{t o r}(r)$, at the coordinate $r$ then amounts to

$$
\sigma_{\text {tot }}(r)=\sum_{i} \sigma_{i}(r)=\sum_{i} D_{i}^{-1} \tilde{\sigma}_{i}(\tilde{r}) D_{i}
$$

where $D_{i}$ is the orientation of the dislocation with respect to the crystal reference system. The dynamics of conservative dislocation motion are described within the framework of viscous flow. The climb dynamics are described by a diffusional law. For conservative dislocation motion the velocity, $u_{\text {glide }}$, can be written

$$
u_{\text {glide }}=\frac{\lambda}{t_{w}+t_{g}} \quad, \lambda=\rho^{-\frac{1}{2}}
$$

where $t_{w}$ is the period which is required to overcome an obstacle within the glide plane and $t_{g}$ the period of glide between two obstacles. $\rho$ is the dislocation density.

$$
t_{w}=\frac{1}{v}=\frac{1}{v_{0} \exp \left(-\frac{Q-F_{\text {glide }} A}{k T}\right)}, v_{0}=\frac{v_{\text {Debeye }}}{1000} \quad, Q=\alpha \frac{1}{2} \mu b^{3}
$$

where $\alpha$ is a constant (here : $\alpha=1$ ), $b$ the Burgers vector, and $\mu$ the shear modulus.

$$
t_{g}=\frac{\lambda}{c F_{\text {glide }}} \quad, c=\text { const. } \approx 0.1
$$

The non-conservative motion of dislocations is described by an exponential approach

$$
u_{\text {climb }}=\frac{D_{0} \exp \left(-\frac{H_{\text {form }}+H_{\text {mig }}}{k T}\right)}{k T} F_{\text {climb }}
$$




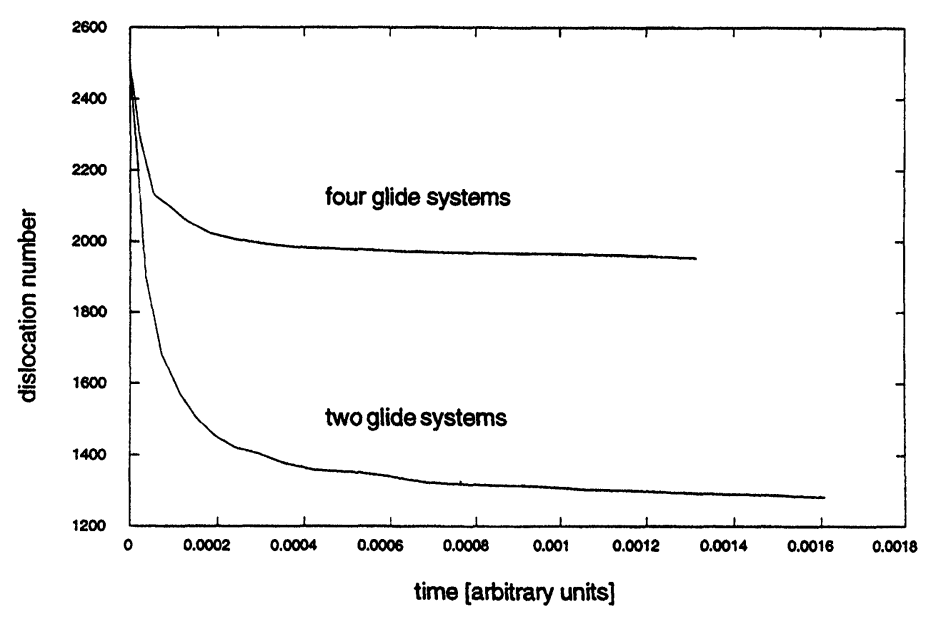

Figure 14 Numerical simulation of the kinetics of static RC using 2D dislocation dynamics. Two grains are investigated. In the first crystal the initial dislocation density, $\rho_{\text {star }}=10^{14} \mathrm{~m}^{-2}$, is distributed on two glide systems prior to the anneal $(1500 \mathrm{~K})$. The two Burgers vectors are inclined by $\pm 45^{\circ}$. In the second crystal the initial dislocation density, $\rho_{\text {start }}=10^{14} \mathrm{~m}^{-2}$, is distributed on four glide systems prior to the anneal $(1500 \mathrm{~K})$. The four Burgers vectors are inclined by $0^{\circ}, \pm 45^{\circ}$, and $90^{\circ}$. The first case is regarded as an example of a grain with a little number of active glide systems (e.g. \{001\} $<110>$ ) and the second one as an example of a grain with a large number of active glide systems (e.g. $\{111\}<110>$ ).

where $H_{\text {form }}$ is the activation energy of vacancy formation and $H_{\text {mig }}$ that of vacancy migration. Depending on the Burgers vectors involved, interacting dislocations may either form sessile configurations, i.e. dipoles or sessile reaction products, or annihilate. Figure 14 shows the kinetics of static RC resulting from internal stresses for both configurations at $1500 \mathrm{~K}$. In this simulation we use data for pure $\mathrm{Fe}$. It is revealed that although both grains have the same initial dislocation density prior to the anneal, $\mathrm{RC}$ proceeds much faster in the grain with two different slip systems. Albeit this simulation neglects the influence of the initial dislocation density it suggests that the RC kinetics considerably depend on the number of slip systems involved. It appears that an increasing number of affected slip systems decreases the frequency of annihilation events and increases the formation frequency of sessile configurations. The latter effect leads to dislocation storage. This aspect is relevant for assessing the orientation dependent degradation of the driving force during annealing prior or parallel to RX. Figures 15 and 16 show the initial dislocation configuration and the dislocation distribution after 15000 steps at $1500 \mathrm{~K}$ (Roters and Raabe 1995).

\subsection{Modelling of the Evolution of Orientation Gradients in Grain Interiors during Cold Rolling}

Whilst in the preceding chapter the orientation dependence of the thermodynamic instability was addressed, we now employ a Taylor type approach to model the origin of misorientations in grain interiors, that is, we address the kinetic instability.

In cold rolled samples local orientation gradients in grain interiors due to the influence of the adjacent crystals (Inokuti and Doherty 1977, 1978, Doherty 1984, Dillamore et 
0 steps

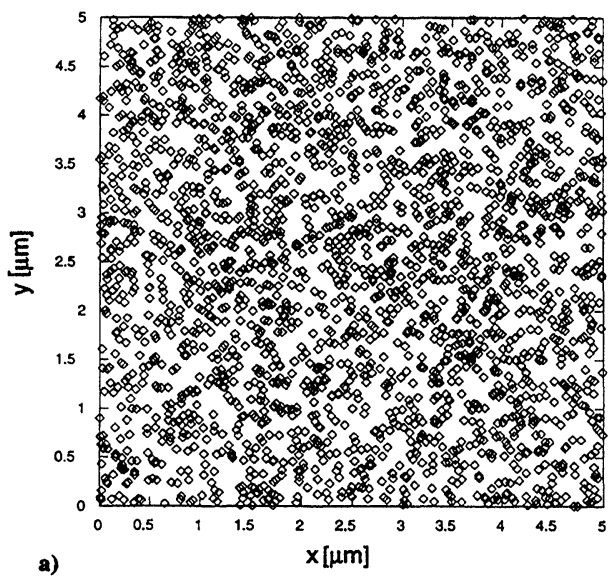

15000 steps

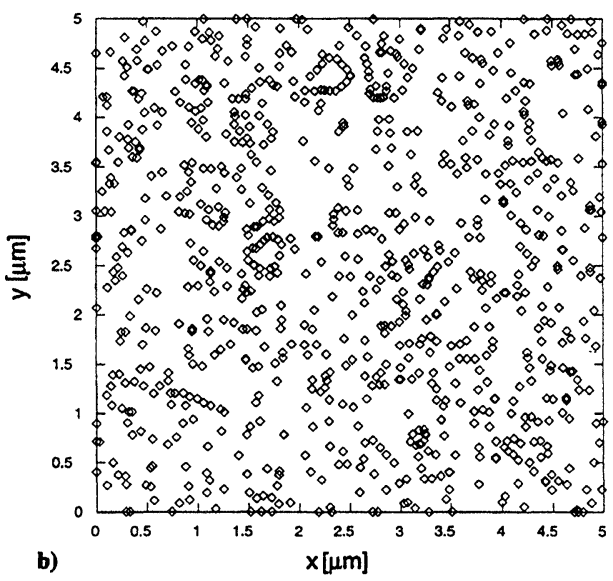

Figure 15 Simulation of the kinetics of static RC using 2D dislocation dynamics. Deformed grain with an initial dislocation density $\rho_{\text {sart }}=10^{14} \mathrm{~m}^{-2}$. The Burgers vectors are distributed on two glide systems prior to the anneal $(1500 \mathrm{~K})$. The Burgers vectors are inclined by $\pm 45^{\circ}$ a) Initial dislocation structure. b) Recovered dislocation structure after 15000 steps at $1500 \mathrm{~K}$.

0 steps

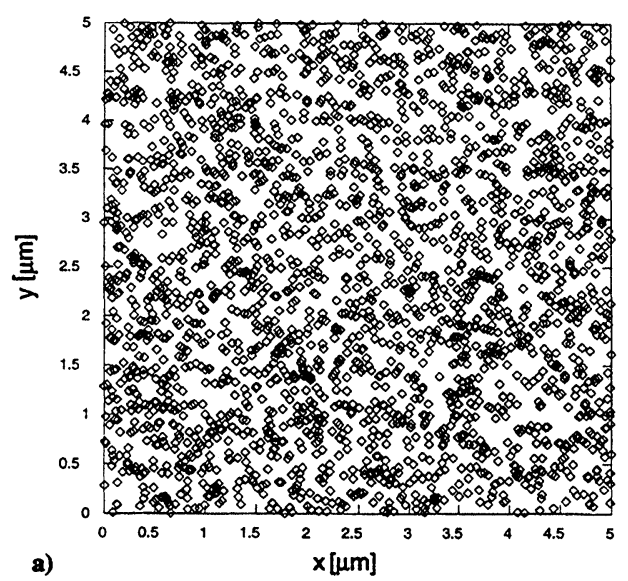

15000 steps

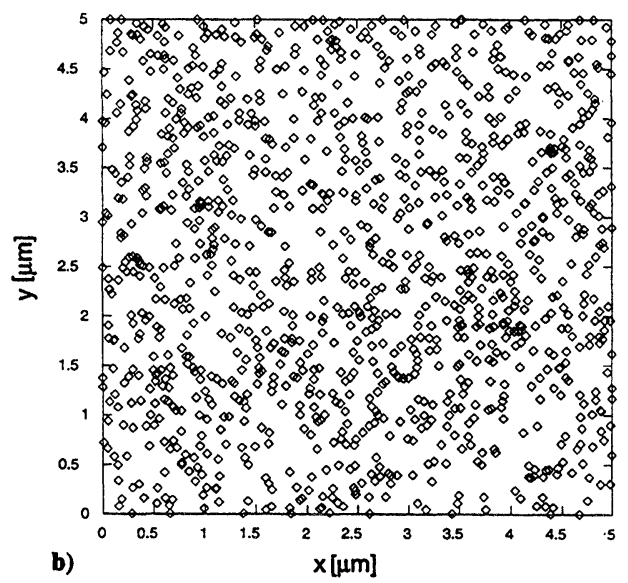

Figure 16 Simulation of the kinetics of static RC using 2D dislocation dynamics. Deformed grain with an initial dislocation density $\rho_{\text {star }}=10^{14} \mathrm{~m}^{-2}$. The Burgers vectors are distributed on four glide systems prior to the anneal $(1500 \mathrm{~K})$. The Burgers vectors are inclined by $0^{\circ}, \pm 45^{\circ}$ and $90^{\circ}$. a) Initial dislocation structure. b) Recovered dislocation structure after 15000 steps at $1500 \mathrm{~K}$. 
al. 1967, 1972, Raabe and Boeslau 1994, Raabe 1994). In our model we assume this interaction, i.e. the strain constraints imposed by the neighboring grains to be decisive for the evolution of orientation gradients (Raabe 1994). If on opposite borders of a grain neighboring crystals with different plastic response are located, different constraints are imposed on either side. The occurrence of different constraints on either side of the grain can lead to different combinations of active slip systems and thus to contrary rotations of different regions in the grain interior. In this simulation the upper bound values of potential orientation gradients are calculated for various degrees of cold reduction and initial orientations of undeformed grains. Details of the model are explained elsewhere (Raabe 1994).

Following the 'Full Constraints Taylor Theory' (FC) (Taylor 1934) deformation of a grain in a polycrystal is determined by the constraints imposed by the neighboring crystals. Compatibility is achieved when all grains undergo the same deformation. The 'Relaxed Constraints Taylor Theory' (RC) assumes also shear strains to occur between adjacent grains (Honneff and Mecking 1978, 1981, Kocks and Chandra 1982). Relaxation of the strain component $\varepsilon_{13}$ corresponds to shear in rolling direction, while $\varepsilon_{23}$ denotes shear in transverse direction $(1=$ rolling direction, $2=$ transverse direction, $3=$ normal direction).

For simulating the upper bound values for the evolution of local misorientations in grain interiors the deformation and rotation of a crystal is investigated close to two opposite grain boundaries, Figure 17. It is assumed that one part of the grain rotates according to the Taylor FC model and the opposite one according to the RC model. For rendering the model into a physically plausible situation one assumes the presence of a neighboring grain which does not admit any strain relaxation on one side of the grain. The simulation of the orientation change of the grain inspected is then carried out using the FC-Taylor model, leading to the final orientation $\mathrm{g}_{\mathrm{FC}}$. On the opposite side an adjacent grain is positioned which admits strain relaxation. The simulation is now carried out using the RC-Taylor model which leads to the orientation $\mathrm{g}_{\mathrm{FC}}$. The resulting orientation difference between $\mathrm{g}_{\mathrm{FC}}$ and $\mathrm{g}_{\mathrm{RC}}$ is then regarded as a measure for maximum orientation gradients which may occur in the crystal interior.

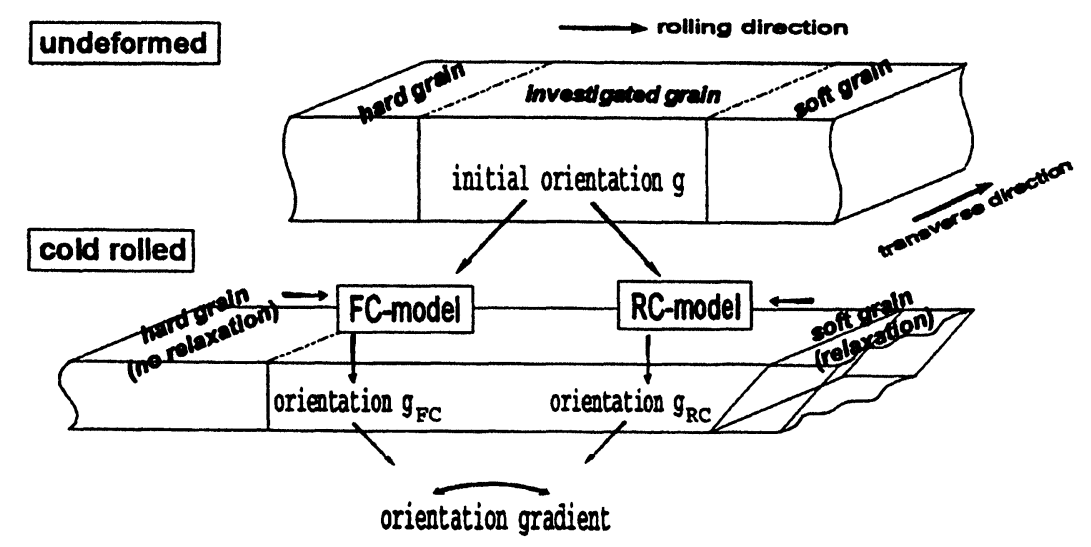

Figure 17 Schematic presentation of the Taylor based model. One part of the grain deforms and rotates according to the Taylor FC model and the opposite one according to the FC model. The resulting orientation difference is a measure for orientation gradients which occur in the crystal interiors. 


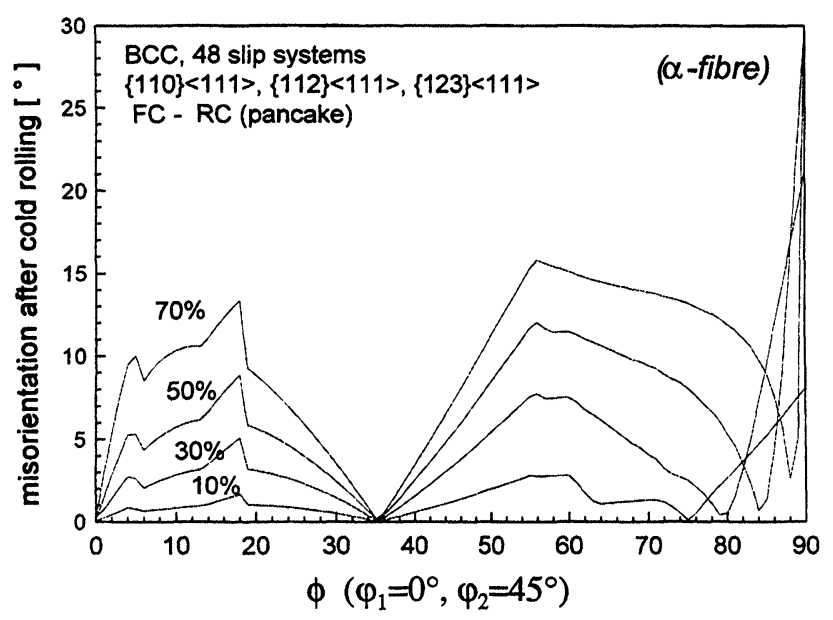

Figure 18 Simulation of maximum misorientations in grain interiors, $12\{110\}<111>, 12\{112\}$ $<111>$ and $24\{123\}<111>$ slip systems. On one side of the deformed grain FC and on the opposite one RC strain constraints (relaxation of $\varepsilon_{23}$ and $\varepsilon_{13}$ ) were assumed, plain strain rolling deformation.

For the simulation shown in Figure 18 the $12\{110\},<111>, 12\{112\}$ $<111>$ and $24\{123\}<111>$ slip systems were used. On one side of the deformed grain FC and on the opposite one RC strain constraints (relaxation of $\varepsilon_{23}$ and $\varepsilon_{13}$ ) were assumed. In the simulation for each pair of stable end orientations ( $\mathrm{g}_{\mathrm{FC}}$ and $\mathrm{g}_{\mathrm{RC}}$ ) the resulting misorientation was computed and expressed in terms of an angle - axis pair. In the fiber diagram, Figure 18, the angles are presented. The simulations were carried out for plain strain rolling deformation.

The simulation shows that the two texture components $\{001\}<110>$ and $\{112\}$ $<110>$ do not reveal any tendency to generate misorientations in their interiors even after $70 \%$ cold reduction. This means both components are stable under FC as well under RC conditions. If different types of models are employed, e.g. a combination of FC and Sachs type deformation (single crystal mode), similar predictions especially for $\{001\}<110>$ are obtained. As was shown by TEM investigations of $\mathrm{Hu}(1962$, 1963), Dillamore (1984) and EBSD studies by Raabe and Boeslau 1994, Raabe 1994, 1995) especially $\{001\}<110>$ oriented grains are also experimentally well known for their weak local misorientations after rolling. Although no microstructural details can be predicted from our approach the simulation suggests in accord with experimental observations that $\{001\}<110>$ and $\{112\}<110>$ oriented crystals have a little potential for the formation of kinetic instabilities.

\subsection{Simulation of Recovery and Primary Recrystallization Using a Modified 3D-Cellular Automaton}

Although various authors recently addressed the simulation of RX textures of bcc steels (Jonas and Urabe 1994, Kestens et al. 1994, Köhler and Bunge 1994, 1995) the influence of RC was not yet sufficiently considered. In this chapter we introduce an approach to model static RC and RX by a modified 3D-cellular automaton (Marx et al. 1995). The model accounts for the orientation dependence of the grain boundary mobility. 
It allows thus to determine the microstructure and texture evolution from a given microstructure state including deformation texture, deformation microstructure and temperature on a sound physical basis. The misorientation between adjacent grains and the spatial orientation of the grain boundary plane determine the mobility of the boundary. For a given misorientation the character of the boundary depends on its orientation in space. Therefore, only a 3D model can provide an adequate approach.

The cellular automaton model used consists of a 3D cubic grid with $100^{3}$ cells with periodic boundary conditions. The model is discrete in space and time. The properties, i.e. the crystallographic texture, and the dislocation density of each cell embedded in this grid are continuously stored. During each step of the model three physical processes, namely RC, nucleation and growth of the nuclei, are sequentially simulated. For simulating nucleation, spheres of a given radius are arranged within the deformed matrix. The kinetics of nucleation are either incorporated as site saturated nucleation or as a constant nucleation rate. During growth of the nuclei spheres grow into the surrounding deformation matrix. The velocity of the grain boundaries depends on their mobility and on the driving force. The first property is expressed in terms of the misorientation between the nucleus and the matrix. The second property is expressed in terms of the difference in dislocation density. All cells at the surface of growing grains are then displaced into the surrounding deformation matrix according to the local grain boundary velocity. The growth of a nucleus stops, when it impinges upon other nuclei.

The driving force for the growth of nuclei is considerably affected by RC. This physical ingredient is incorporated into the simulation by a reduction of the dislocation density in all non-recrystallized cells of the grid. The time law of this reduction is assumed to be an exponential degradation with time. If the dislocation density within a cell reaches a critical value, which is necessary for a further propagation of the grain boundaries, the cell is identified as being recovered. The simulation is terminated when all cells within the grid are either recrystallized or recovered.

The spatial limitation of the model, however, requires an upper ceiling for the displacement distance during one step of the model. To retain this limit and to simulate the different kinetics connected with RC and RX, we introduced an adaptability of the time increments. The time increment that relates to one step of the model is specified by the maximum displacement and the maximum grain boundary velocity during this step. The calculation of RC kinetics takes in account the sum of all time increments. Further details of the model are discussed elsewhere (Marx et al. 1995).

The initial microstructure consisted of 30 grains scaled by the above mentioned grid. The orientations of the grains represented a typical cold rolling texture of a bcc alloy, Figure 19a. Nucleation was assumed to be spatially random and site saturated. Oriented nucleation was held responsible for the development of RX texture.

The results of the calculations without consideration of RC are in good accord with typical experimental data which are known from the literature (e.g. Raabe and Lücke 1993), Figure 19b. The orientation distribution after RX consists of a strong $\gamma$-fiber which has developed at the expense of the $\alpha$-fiber, that was present in the cold rolling texture. Similar texture predictions were recently published by Köhler and Bunge (1995). If $\mathrm{RC}$ is taken into account in addition to $\mathrm{RX}$ deviating results are observed. Figure $19 \mathrm{c}$ shows the texture of a simulated microstructure, which consists of $91 \%$ recrystallized and $9 \%$ recovered cells. This texture shows a strong $\gamma$-fiber, which can be attributed to the recrystallized grains, and a weak $\{001\}<110>$ texture component, which is identified with the recovered deformation matrix. With a recovered volume fraction of $30 \%$ the $\alpha$-fiber becomes even more pronounced at the expense of the orientation 

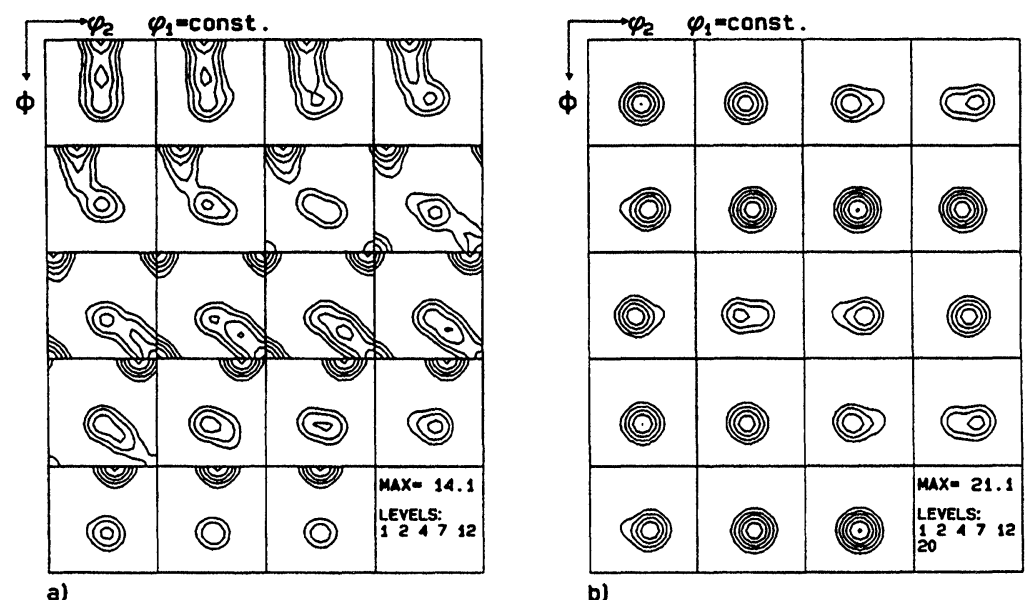

b)
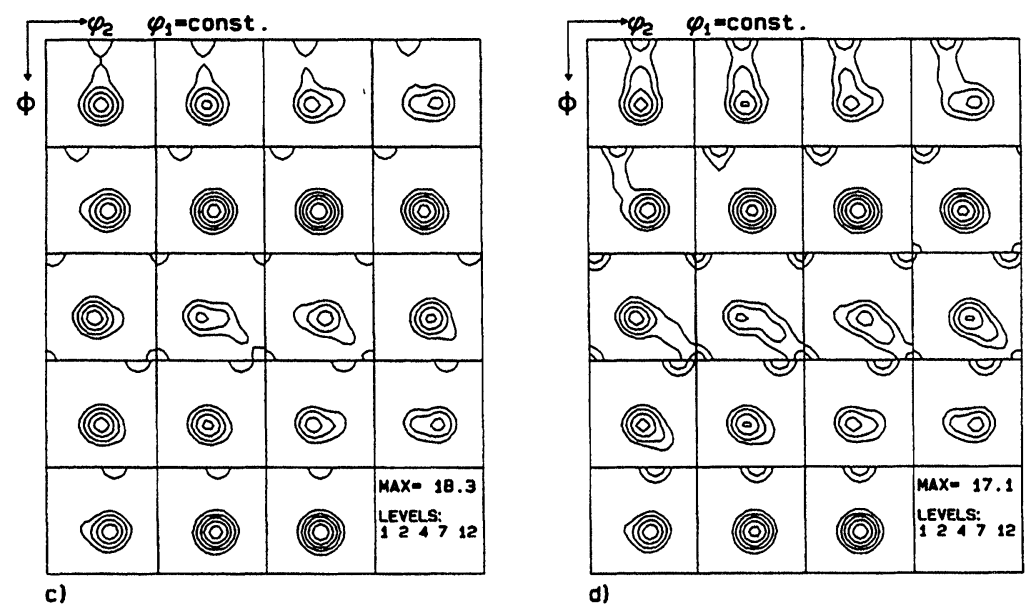

Figure 19 Simulation of the influence of the orientation dependence of recovery on the final annealing texture using a 3D cellular automation. a) Initial bcc cold rolling texture consisting of 30 grains. b) RX texture without contribution of recovery. Nucleation was assumed to be spatially random and site saturated. c) Annealing texture consisting of $91 \%$ recrystallized and $9 \%$ recovered cells.

d) Annealing texture consisting of $70 \%$ recrystallized and $30 \%$ recovered cells.

density of the $\gamma$-fiber, Figure 19d. The latter simulation indeed covers the preservation especially of the $\{001\}<110>$ component as observed experimentally, Figures 6, $7,9,12,13$.

\section{DISCUSSION}

From the preceding chapters we can extract the following observations which are relevant for understanding $\mathrm{RC}$ textures of bcc metals. 
Experimental:

- The kinetics of RC and RX considerably depend on the affected orientation. This observation holds for both cold rolled and annealed and hot rolled specimens.

- In $\{001\}<110>$ and related $\{\mathrm{hlk}\}<110>$ oriented grains $\mathrm{RX}$ is delayed in case of a small $\left(\mathrm{d}_{\text {grain }} \approx 10-100 \mu \mathrm{m}\right)$ and even suppressed in case of a large initial grain size $\left(d_{\text {grain }} \approx m m\right)$. Such sluggish $R X$ behavior leaves room for strong $R C$ of the grains affected.

- Even at the final stage of $\operatorname{RX}\{001\}<110>$ oriented crystals do not reveal nuclei inside the grain. It was observed that nuclei stemming from the former grain boundary or from neighboring grains grow into $\{001\}<110>$ oriented crystals.

- In case of a large grain size in $\{112\}<110>$ oriented grains both RX and RC were observed. However, nucleation in these grains was not entirely suppressed as in $\{001\}<110>$ oriented crystals. In case of a small initial grain size $\{112\}$ $<110>$ oriented crystals revealed a behavior which was similar to that of $\{111\}$ $<110>$ grains.

- Grains with $\{111\}<\mathrm{uvw}>$ orientation have a strong tendency to recrystallize. In case of a large grain size especially in $\{111\}<112>$ grains nucleation is promoted by plastic instabilities such as shear bands. In samples with large grains it was observed that a certain volume fraction of $\{111\}<110>$ oriented crystals was generated inside $\{111]<112>$ grains and vice versa. Microtexture investigations of rolled and partially recrystallized polycrystals revealed that $\{111\}<110>$ is formed at the early stages of RX.

- $\gamma$-fiber grains typically contain large orientation gradients. In contrast, $\{001\}$ $<110>$ oriented crystals do not contain misorientations in their interiors which suffice to provide kinetic instabilities.

- Grains which are surrounded by both soft and hard grains have a larger tendency to generate large local misorientations, than grains which are only surrounded by either hard or soft grains.

Simulation:

- Simulations based on 2D dislocation dynamics suggest that the kinetics of static $\mathrm{RC}$ depend on the number of Burgers vectors involved during plastic deformation prior to the anneal. According to this computer experiment $\mathrm{RC}$ in grains with a small number of involved slip systems proceeds much faster than in grains with a large number of involved slip systems. Consequently, the driving force which remains for $\mathrm{RX}$ depends on the orientation, even if in a simplified approach, identical dislocation densities are assumed.

- The kinetic instability criterion was simulated using a modified Taylor type approach in which different strain constraints were assumed on opposite sides of a grain. The results suggests that $\{111\}<\mathrm{uvw}>$ and $\{110\}<\mathrm{uvw}>$ oriented grains have a large tendency to generate local misorientations sufficient for nucleation. In contrast, the $\{001\}<110>$ and $\{112\}<110>$ component do not reveal any tendency to generate local orientation gradients. 
- Incorporating both experimental and simulated results the microstructure and texture of recrystallized and partially recovered bcc polycrystals can be successfully described using a deterministic 3D cellular automation.

Based on these observations the strong orientation dependence of $\mathrm{RC}$ in bcc metals can be understood in two ways:

1. The first approach is based on the assumption that the driving force is reduced by $\mathrm{RC}$ so that the mechanic instability criterion for $\mathrm{RX}$ is violated. $\mathrm{RC}$ and $\mathrm{RX}$ reveal different kinetic laws. Whereas in the first case the properties change according to $\exp \left(-t / \tau_{R C}\right)$, in the latter case they change according to exp $\left(-t / \tau_{R C}\right)^{q}$, where $t$ is the annealing time, $\tau_{\mathrm{RC}}$ the kinetic constant of $\mathrm{RC}, \tau_{\mathrm{RX}}$ the kinetic constant of $\mathrm{RX}$ and q a constant within the range 3-4. The latter law is especially characterized by an incubation period in the beginning and grain impingement at the end of RX. Due to such kinetics it is conceivable that if RC is strong enough to reduce the total driving force, the movement of newly formed high-angle grain boundaries can be gradually slowed down.

The simulation of the RC kinetics indeed showed that in grains with a small number of involved Burgers vectors $\mathrm{RC}$ proceeds much faster than in grains with a large number of Burgers vectors. By using Taylor models it is readily shown that for the deformation of $\{001\}<110>$ oriented grains only two (flat grain limit, pancake type strain constraints) or four slip systems (full strain constraints) satisfy mutual compatibility of the crystals during plastic deformation. In contrast, deformation of $\{111\}<$ uvw > oriented crystals generally requires a larger number of equally employed slip systems. Hence it is indeed conceivable that RC in $\{111\}$ $<$ uvw $>$ oriented crystals proceeds more sluggish than in $\{001\}<110>$ oriented grains.

However, for interpreting the enormous differences observed the above argumentation seems relevant but not crucial. The assumption that the orientation dependence of the degradation of the driving force during $\mathrm{RC}$ is the main source for the orientation dependence of $\mathrm{RC}$ and $\mathrm{RX}$ is questioned by three observations. First, although the kinetics of non-conservative dislocation motion in $\{001\}$ $<110>$ oriented crystals seems to favor RC instead of RX, the stored dislocation density is typically lower than in $\{111\}<\mathrm{uvw}>$ oriented crystals. This fact suggests that the driving force of RC is larger in $\{111\}<\mathrm{uvw}>$ than in $\{001\}<110>$ oriented crystals. This effect might lead to a compensation of the difference in kinetics which was predicted by the dislocation simulation, Figures 14-16. Owing to this uncertainty it appears pertinent to tackle the influence of both the number of Burgers vectors and of the dislocation density on the kinetics of $\mathrm{RC}$ in more detail (Roters and Raabe 1995). Second, RC is not an isolated process but a preprocess to RX during which nucleation is promoted rather than suppressed. That is to say that rapid $\mathrm{RC}$ in $\{001\}<110>$ should lead to a large number of nuclei which is obviously not the case. Third, in case of a small grain size it was observed that $\{001\}<110>$ oriented crystals are consumed by growing nuclei which proceed from the former grain boundary or from neighboring grains. This experience implies that $\{001\}<110>$ oriented grains indeed reveal a net driving force sufficient for $\mathrm{RX}$ if only the nuclei are provided.

2. The second approach is based on the assumption that although a net driving force potentially exists, thermodynamic and kinetic instabilities do not occur in $\{001\}$ 
$<110>$ oriented grains. For generating new high-angle grain boundaries during nucleation the presence of sufficiently large local misorientations in the grain interior after deformation is required. However, texture gradients are rarely observed in grains with $\{001\}<110>$ orientation. This experience is covered by observations on deformed silicon-iron single crystals (Hu 1962, 1963). Also in polycrystalline specimens (Dillamore 1968, 1972, Raabe and Boeslau 1993, 1994) it was observed experimentally and confirmed theoretically by employment of various Taylor type models that $\{001\}<110>$ oriented crystals do not change their initial orientation during rolling deformation. As a consequence the as-rolled crystals show a uniform microstructure without deformation banding. Furthermore, the slip systems required for deformation of a (001) [110] oriented grain under FC conditions, i.e. (101)

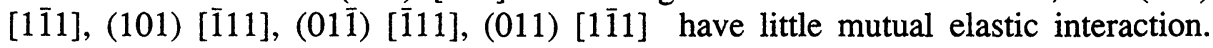
It is assumed that such conditions promote weak strain hardening, homogeneous dislocation substructures with large cell sizes and weak local misorientations. Following the approach of $\mathrm{Hu}(1962,1963)$, viz. that coalescence of subgrains represent a leading mechanism for the formation of nuclei the reluctance of $\{001\}$ $<110>$ grains to recrystallize appears conceivable since its driving force depends on both the cell size and the misorientations imposed by the cell walls.

On the basis of the present experimental results on polycrystals and corresponding observations on single crystals (Hu 1962,1963) strong $\mathrm{RC}$ of $\{001\}<110>$ oriented crystals is interpreted in terms of the suppression of $\mathrm{RX}$, more precisely to the avoidance of thermodynamic and kinetic instabilities rather than in terms of special properties of the RC kinetics.

\section{CONCLUSIONS}

A large variety of texture and microstructure data of hot rolled and cold rolled and annealed bcc metals and alloys was reviewed with respect to the correlation of recovery and texture. The data substantiated that mainly two conditions promote strong recovery of certain bcc deformation texture components (e.g. $\{001\}<110>$ ), namely, the absence of kinetic instabilities, and the absence of a thermodynamic and mechanic instability. It was shown that all three types of instabilities depend on the grain orientation. The experimental observations were complemented by numerical simulations. The influence of the number of Burgers vectors involved during preceding deformation on the kinetics of static recovery was studied using $2 \mathrm{D}$ dislocation dynamics. The orientation dependent tendency for the formation of local misorientations in the grain was simulated using a Taylor type approach assuming different constraints on either side of the grain. The influence of the orientation dependence of recovery on the final annealing texture was then simulated using a 3D cellular automaton. From both experiment and simulation two main criteria were extracted which allow to access whether recovery or recrystallization prevails during annealing. The first criterion is the orientation dependence of the driving force which depends on the recovery kinetics. The second criterion is the orientation dependence of the tendency to form kinetic instabilities. It was suggested that the influence of the latter criterion prevails.

\section{Acknowledgements}

This investigation was supported by the Deutsche Forschungsgemeinschaft (DFG) through the Collaborative Research Center 370 "Integrative Werkstoffmodellierung". 


\section{References}

Beynon, J. H., Brown, P. R., Mizban, S. I., Ponter, A. R. S. and Sellars C. M. (1987). in "computational techniques for predicting material processing defects", ed. M. Predeleanu, p. 19-28, Amsterdam, Elsevier.

Bunge, H. J. (1982). Texture Analysis in Materials Science, Butterworths, London.

Cahn, R. (1966). in "Recrystallization, Grain Growth and Textures", ed. H. Margolin, ASM, Metals Park, Ohio, 99.

Dillamore, I. L., Morris, P. L., Smith, C. J. E. and Hutchinson, W. B. (1972). Proc. Roy. Soc., 329A, 405.

Dillamore, I. L. (1984). in “Recrystallization of Metallic Materials", ed. F. Haessner Dr. Riederer Verlag GmbH, Stuttgart, 223.

Doherty, R. D. (1984). in "Recrystallization of Metallic Materials", ed. F. Haessner Dr. Riederer Verlag $\mathrm{GmbH}$, Stuttgart, 23.

Engler, O. and Gottstein, G. (1992). Steel Research, 63, 413.

Fedosseev, A., and Raabe, D. (1994). Scripta metall. 30, 1.

Fedosseev, A., Raabe, D. and Gottstein, G. (1994). Materials Science Forum 157-162, 1991.

Gottstein, G., (1984). Rekristallisation metallischer Werkstoffe (DGM Verlag).

Haessner, F. (1984). Recrystallization of Metallic Materials, Dr. Riederer Verlag GmbH, Stuttgart.

Hirth, J. P. and Lothe, J. (1968). Theory of Dislocations, McGraw-Hill Book Company.

Honneff, H. and Mecking, H. (1978). Proceedings 5th Int. Conf. on Tex. of Mat. ICOTOM 5, ed. G. Gottstein and K. Lücke, Springer Verlag, 265.

Honneff, H. and Mecking, H. (1981). Proceedings 6th Int. Conf. on Tex. of Mat. ICOTOM 6, ed. S. Nagashima, Iron and Steel Inst. of Japan, 347.

Houdremont, E. (1956). Handbuch Sonderstahlkunde, 3. Aufl., Springer Verlag, 623.

Hu, H. (1962). Trans. AIME 224, 75.

Hu, H. (1963). Recov. and Recryst. of Metals, ed. L. Himmel, Wiley and Sons, N. Y., 311.

Hutchinson, W. B. (1989). Acta Metall. 37, 1047.

Hutchinson, W. B. (1984). Intern. Mat. Rev. 29, 25.

Inokuti, Y. and Doherty, R. D. (1978). Acta Metall. 26, 61.

Inokuti, Y. and Doherty, R. D. (1977). Texture 2, 143.

Jonas, J. J. and Urabe T. (1994). Proceedings Int. Forum on Physical Met. of IF Steels, Tokyo, Iron and Steel Inst. of Japan, 77.

Kestens, L. Köhler, U., van Houtte, P., Aernoudt, E. and Bunge, H. J. (1994). Materials Science Forum 157-162, 1783.

Kern, R. and Bunge. H. J. (1984). Proceedings 7th Int. conf. on Tex. of Mat. ICOTOM 7, ed. C. M. Brakman, P. Jongenburger and E. J. Mittenseijer, Netherland Soc. for Mater. Sci., Noordwijkerhout, 89.

Klimanek, P. (1995). Institut für Metallkunde, TU Bergakademie Freiberg, priv. Comunic.

Kocks, U. F. and Chandra, H. (1982). Acta Metall., 30, 695.

Köhler, U. and Bunge, H. J. (1994). Materials Science Forum 157-162, 1803.

Köhler, U. and Bunge, H. J. (1995). Textures and Microstructure 23, 87.

Lebrun, J. L., Maeder, G., and Parniere, P. (1978). Proc. 5th Int. Conf. on Textures of Materials Bd. 2, Springer Verlag, ed. G. Gottstein, K. Lücke, 513.

Lindh, E., Hutchinson, B., and Bate, P. (1994). Mat. Sci. Forum 157-162, 997.

Marx, V., Reher, F. and Gottstein, G. soon to be published.

McLaren, A. J. and Sellars, C. M. (1992). Mater. Scien. and Techn. 8, 1090.

McLaren, A. J. and Sellars, C. M. (1993). Proceedings of International Conference on Strip Casting, Hot and Cold Working of Stainless Steels, Quebec, Canada, 1993, ed. N. D. Ryan, A. J. Brown, H. J. McQueen, The Metall. Society of Canad. Inst. of Met, 107.

Michalak, J. T. and Paxton, H. W. (1961). Trans. AIME 221, 850.

Nabarro, F. R. N. (1989). Acta Metall., 37, 1521.

Nes, E. (1995). Acta Metall., 43, 2189.

Österle, W. and Wever, H. (1981). Z. Metallkunde 72, 230.

Plutka, B. and Hougardy, H. P. (1991). Textures and Microstructure 14-18, 697.

Raabe, D. (1994). Phys. Stat. Sol. (b). 181, 291.

Raabe, D. and Boeslau, J. (1994). Proceedings 15th RISØ Int. Sympos. on Mat. Science, eds.: S. I. Andersen, J. B. Bilde-Sorensen, T. Lorentzen, O. B. Pedersen and N. J. Sorensen. RIS $\emptyset$ Nat. Lab., Roskilde, Denmark, 481.

Raabe, D. and Lücke, K. (1992). Scripta Metall. 27, 1533. 
Raabe, D. and Lücke, K (1994). Materials Science Forum 157-162, 597.

Raabe, D., Klinkenberg, C. and Lücke, K. (1993). Steel Research 64, 262.

Raabe, D. (1995). Steel Research 66, 222.

Raabe, D. and Lücke, K. (1993) Materials Science and Technology 9, 302.

Raabe, D., Lücke, K., and Gottstein, G. (1993). Journal de Physique IV, colloque C7, supplément au Journal de Physique III 3, 523.

Raabe, D., Schlenkert, G., Weisshaupt, H. and Lücke K. (1994). Materials Science and Technology 10, 229

Raabe, D., and Ylitalo, M. (1995). Met. Transact. A, in press.

Raabe, D and Lücke, K. (1993). Proceedings of International Conference on Strip Casting, Hot and Cold Working of Stainless Steels, Quebec, Canada, 1993, ed. N. D.Ryan, A. J. Brown, H. J. McQueen, The Metall. Society of Canad. Inst. of Met. 221.

Roters, F. and Raabe, D. (1995). soon to be published.

Smith, C. J. E. and Dillamore, I. L. (1974). Metal Science 8, 73.

Takechi, H., Kato, H. and Nagashima, S. (1968). Trans. AIME 242, 56.

Taylor, G. I. (1938) Journ. Inst. Met. 62, 307.

Venables, J. and Harland, C. (1973). Philos. Mag. 27, 1193.

Walter, J. and Koch, E. (1963). Acta Metall., 11, 923.

Wassermann, G., Grewen, J. (1962). Texturen metall. Werkstoffe, Berlin-Göttingen-Heidelberg, Springer Verlag. 